\title{
ANÁLISE DOS COBENEFÍCIOS EM PROL DO DESENVOLVIMENTO SUSTENTÁVEL DOS PROJETOS BRASILEIROS DE TROCA DE COMBUSTÍVEL: UM ESTUDO DE CASO DA DORI ALIMENTOS
}

\author{
ANALYSIS OF CO-BENEFITS FOR THE SUSTAINABLE DEVELOPMENT OF BRAZILIAN FUEL SWITCH \\ PROJECTS: A CASE STUDY OF DORI ALIMENTOS
}

\section{ANÁLISIS DE LOS COBENEFICIOS EN PRO DEL DESARROLLO SOSTENIBLE DE LOS PROYECTOS BRASILEÑOS DE CAMBIO DE COMBUSTIBLE: UN ESTUDIO DE CASO DE LA DORI ALIMENTOS}

DANIELLE SOARES PAIVA

Universidade Federal da Bahia - Brasil paivadani@hotmail.com

\author{
MARIA DE FÁTIMA BARBOSA GÓES \\ Doutoranda \\ Universidade Federal da Bahia - Brasil \\ mfbgoes@gmail.com \\ JOSÉ CÉLIO SILVEIRA ANDRADE \\ Doutor \\ Universidade Federal da Bahia - Brasil \\ jcelio.andrade@gmail.com
}

Submetido em: 02/03/2015 Aprovado em: 16/12/2015

Doi: alcance.v22n4.p474-489

\section{RESUMO}

Este estudo apresenta resultados parciais de uma pesquisa que tem por objetivo analisar os cobenefícios em prol do desenvolvimento sustentável dos projetos de troca de combustível, cujos créditos são negociados no mercado voluntário de carbono brasileiro. Para tanto, os Documentos de Concepção dos Projetos (DCP) foram analisados utilizando uma matriz analítica que tomou por base estudos da United Nations Framework Convention on Climate Change (UNFCCC, 2012) sobre cobenefícios do mercado regulado de carbono. Além dos DCPs, outros documentos que apoiaram na concepção dos projetos foram buscados. Assim, realizou-se uma pesquisa bibliográfica e documental, de caráter exploratório, além de um estudo de caso ilustrativo da empresa Dori Alimentos. Os resultados indicam que dos projetos de mudança de combustível decorrem dois cobenefícios principais: desenvolvimento ou difusão local da tecnologia e da preservação dos recursos naturais, ficando os demais relegados a segundo plano. Conclui-se que os projetos de troca de combustível são pobres em cobenefícios, acompanhando o comportamento do cenário internacional e nacional para os mercados regulado e voluntário de carbono.

Palavras chave: Mercado Voluntário de Carbono. Cobenefícios. Projetos de Troca de Combustível.

\section{ABSTRACT}

This study presents partial results of a study to analyze the co-benefits for sustainable development of fuel switch projects whose credits are traded on the voluntary Brazilian carbon market. Project Design Documents (PDD) were analyzed using an analytical matrix that was based on studies of the United Nations Framework Convention on Climate Change (UNFCCC, 2012) on co-benefits of the regulated carbon market. In addition to the PDDs, other documents that supported the design of projects were sought. An exploratory bibliographical and documentary review was carried out, and an illustrative case study of the food company Dori Alimentos. The 
results indicate that there are two main co-benefits associated with fuel switch projects: development or local diffusion of technology, and preservation of natural resources, with the other benefts being relegated to a less important position. It is concluded that fuel switch projects are low in co-benefits, following the behavior of the international and national scenarios for regulated and voluntary carbon markets.

Key Words: Voluntary Carbon Market. Co-benefits. Fuel Switch Projects.

\section{RESUMEN}

Este estudio presenta los resultados parciales de una investigación que tiene por objetivo analizar los cobeneficios en pro del desarrollo sostenible de los proyectos de cambio de combustible, cuyos créditos son negociados en el mercado voluntario de carbono brasileño. Para ello fueron analizados los Documentos de Concepción de los Proyectos (DCP) utilizando una matriz analítica que tomó por base estudios de la United Nations Framework Convention on Climate Change (UNFCCC, 2012) sobre los cobeneficios del mercado regulado de carbono. Además de los DCPs, se buscaron otros documentos que se apoyaran en la concepción de los proyectos. De este modo, se realizó una investigación bibliográfica y documental, de carácter exploratoria, además de un estudio de caso ilustrativo de la empresa Dori Alimentos. Los resultados indican que de los proyectos de cambio de combustible resultan dos cobeneficios principales: desarrollo o difusión local de la tecnología y de la preservación de los recursos naturales, quedando los demás relegados a segundo plano. Se concluye que los proyectos de cambio de combustible son pobres en cobeneficios, acompañando el comportamiento del escenario internacional y nacional para los mercados regulado y voluntario de carbono.

Palabras clave: Mercado Voluntario de Carbono. Cobeneficios. Proyectos de Cambio de Combustible.

\section{INTRODUÇÃO}

A constatação da gravidade dos efeitos das mudanças climáticas para o meio ambiente e para o modo de vida da população estabelece desafios inadiáveis para as ações e políticas de mitigação e/ou adaptação, envolvendo, principalmente, ações que sejam capazes de reverter a atual situação de concentração na atmosfera dos Gases de Efeito Estufa (GEE), principais responsáveis pelo aquecimento global e pelas mudanças climáticas.

Em 2005, após intenso debate político, entrou em vigor o Protocolo de Kyoto, acordo multilateral internacional considerado marco político mundial em questões relacionadas ao meio ambiente. $O$ Protocolo de Kyoto articulou 175 países (dos quais $36 \mathrm{com}$ compromissos reais de redução de emissão) em torno do compromisso de combate às mudanças climáticas, por meio de três mecanismos de flexibilização de emissões de GEE. Tais mecanismos são: a implementação conjunta (JI - Joint Implementation), que permite que países industrializados compensem suas emissões financiando projetos de redução de GEE em outros países industrializados; o Comércio de Emissões (CE), que possibilita aos países trocarem suas emissões permitidas; e os Mecanismos de Desenvolvimento Limpo (MDL), que permitem aos países industrializados alcançarem suas metas individuais por meio de projetos implantados em países em desenvolvimento (GOLDEMBERG, 2005).

O Mecanismo de Desenvolvimento Limpo (MDL) - 0 único que permite também a participação de países em desenvolvimento - constitui-se em uma ferramenta de mercado que visa equilibrar desenvolvimento econômico e meio ambiente, permitindo que as reduções de emissões de gases de efeito estufa decorrentes de sua implementação sejam comercializadas como créditos de carbono. O MDL tem como objetivo a redução de emissão de GEE e a promoção do desenvolvimento sustentável em países em desenvolvimento, por meio de projetos financiados por países desenvolvidos (SIMONI, 2009). Assim, o MDL trouxe a possibilidade de participação de países não obrigados pelo acordo ao cumprimento das metas fixadas, a exemplo do grupo dos BRICs - Brasil, Rússia, Índia e China, que tem efetivamente aproveitado esta oportunidade.

Para implementação do mecanismo de Comércio de Emissões, foi criado o Mercado Regulado de Carbono (MRC), um ambiente institucional no qual os participantes estão submetidos às legislações e às normas nacionais ou globais, que estabelecem critérios e regras para concepção de projetos e comercialização das Reduções Certificadas de Emissões (RCE) oriundas dos projetos de MDL, também denominadas de créditos de carbono. 
Trata-se de um mercado com grande potencial de crescimento em um país em desenvolvimento, como o Brasil. Além de obter vantagens financeiras com a venda dos créditos, as empresas brasileiras podem aliar a sua imagem à preocupação com o meio ambiente e com o futuro da humanidade e do planeta. Com os projetos de MDL, surgem possibilidades de investimentos em tecnologias mais limpas pelas empresas das nações que os adotam, e ainda de obtenção de cobenefícios, ou seja, benefícios que vão além da redução das emissões dos gases de efeito estufa e contribuem para a promoção do desenvolvimento sustentável.

Além do mercado regulado de carbono, outro mercado fora do arcabouço do Protocolo de Kyoto foi criado: o Mercado Voluntário de Carbono (MVC). Este mercado constitui-se em espaços nos quais as negociações de créditos de carbono, intitulados Verified Emission Reduction (VER), se dão por meio de diversos agentes - como governos, empresas, Organizações Não Governamentais (ONGs) e indivíduos - que estabelecem entre si as regras, as normas e os padrões de certificação (SIMONI, 2009; SOUZA; PAIVA \& ANDRADE, 2011). $O$ interesse destes atores no MVC está pautado no gerenciamento de seus impactos em relação às mudanças do clima, sua imagem, reputação, interesses em inovações tecnológicas para redução de GEE, legitimidade, necessidade de se prepararem para regulações futuras e/ou planos de revenda de créditos de carbono, lucrando com as comercializações (IBRI, 2009).

Inicialmente utilizado por empresas e indivíduos de países não signatários do Protocolo de Kyoto como os Estados Unidos -, com o passar do tempo o MVC tornou-se também uma alternativa aos rigorosos critérios do mercado regulado. A participação e/ou migração de empresas para esse mercado vem se dando em função da maior celeridade nos procedimentos de validação de projetos em comparação ao mercado regulado, o que maximiza o retorno do investimento. Assim, dentre os projetos desenvolvidos no MVC, estão: a) projetos com metodologias de pequena escala, não viáveis do ponto de vista econômico no mercado regulado; b) projetos que não atendem aos critérios estabelecidos pelo $\mathrm{MDL}$; e $\mathrm{c}$ ) projetos que já computaram créditos retroativos, ou seja, créditos computados antes mesmo do registro do projeto (SIMONI, 2009).

Esses dois mercados vêm se expandindo no mundo com a crescente comercialização de créditos de carbono, tendo como foco a redução das emissões globais, respaldados, também, na concepção empresarial de crescimento do século XXI, que tem agregado novos aspectos nos planos corporativos, visando a benefícios sociais e ambientais, além dos econômicos (BAYON et al., 2009).

No cenário de reflexão que se estabelece após o fim do primeiro período de vigência do Protocolo de Kyoto (2008-2012), inúmeras críticas aos seus resultados quanto à promoção do desenvolvimento sustentável $\mathrm{e}$ às ações de mitigação das mudanças climáticas vêm sendo feitas (SOUTHSOUTHNORTH, 2004). A insuficiência das contribuições é destacada, por exemplo, por Boyd et al. (2009) e por Bozmoski, Lemos e Boyd (2008), quando afirmam que estes projetos falharam na promoção do desenvolvimento sustentável, especialmente pela concentração geográfica e setorial, privilegiando regiões mais ricas em detrimento das mais pobres e tecnologias de caráter mais corretivo e de baixo conteúdo de inovação tecnológica.

Assim, este artigo, fruto de uma pesquisa para uma tese de doutorado, tem como objetivo analisar os cobenefícios em prol do desenvolvimento sustentável - para além da redução de GEE - dos projetos de carbono do escopo de troca de combustível registrados no mercado voluntário de carbono brasileiro. Decorre do objetivo principal os objetivos específicos de caracterizar o mercado voluntário de carbono no Brasil, assim como o perfil dos projetos brasileiros de troca de combustível e seus cobenefícios.

Para tanto, será apresentado no item fundamentação teórica o estado da arte dos mercados regulados e voluntários de carbono e a abordagem de cobenefícios de projetos de redução de GEE. A seção de procedimentos metodológicos traz as escolhas e os aspectos metodológicos necessários para 0 desenvolvimento desta pesquisa. Na seção de resultados, são apresentados o Mercado Voluntário de Carbono no Brasil, o perfil dos projetos brasileiros de troca de combustível e seus cobenefícios, incluindo os cobenefícios encontrados na análise documental de todos os projetos e no estudo de caso ilustrativo do projeto Dori. As considerações finais encerram o trabalho e apontam para trabalhos futuros.

\section{FUNDAMENTAÇÃO TEÓRICA}

Este trabalho fundamenta-se nos conceitos de mercado de carbono, incluindo tanto o mercado regulado quanto o voluntário, e de cobenefícios dos projetos do mercado de carbono para o desenvolvimento sustentável, os quais se referem aos benefícios não associados diretamente à redução das emissões dos gases de efeito estufa, a qual é derivada dos projetos de MDL. 


\section{Mercado de Carbono}

O mercado de carbono pode ser definido como a "compra e venda de licenças para emissões (direito de poluir) ou reduções de emissões (offsets) que foram respectivamente ou distribuídos por um órgão regulatório ou gerados por projetos de redução de emissões de GEE" (PETERS-STANLEY; YIN, 2013, p. 05). De acordo com Kollmuss, Zink e Polycarp (2008), nesse mercado é realizada a compensação de carbono, onde um agente paga outro agente para reduzir as emissões dos gases em outros lugares, em busca da "neutralização" da sua pegada de carbono. Trata-se de um ambiente em que se comercializam os chamados "créditos de carbono", ativos financeiros que representam o volume de dióxido de carbono reduzido ou removido da atmosfera.

O Mercado de Carbono atualmente opera nas modalidades regulada e voluntária. A primeira rege-se pelas normas e regras estipuladas pelo Protocolo de Kyoto (PK) e é instrumentalizada pela Organização das Nações Unidas (ONU). A segunda não se vincula oficialmente àquele marco legal, mas, de forma mais flexível, permite uma maior participação e diversidade de atores (governo, organizações não governamentais - ONGs, empresas privadas, pessoas físicas, etc.), delimitando-se a partir da relação entre eles e da atuação de Padrões de Certificação (PCs) definidores de regras de concepção de projetos.

Assim, enquanto no mercado regulado são comercializadas as Reduções Certificadas de Emissões (RCE); o mercado voluntário - também conhecido como mercado alternativo a Kyoto - constitui-se em um ambiente em que são negociados créditos de carbono, intituladosVerified Emission Reduction(VER) (SIMONI, 2009).

O Mercado Voluntário de Carbono, segundo dados da Peters-Stanley e Yin (2013), embora represente apenas $2 \%$ do volume transacionado de $\mathrm{CO}_{2}$ no mercado de carbono global, vem crescendo em volume, apesar de decrescer em termos do valor dos créditos comercializados, levando a um decréscimo dos preços (Tabela 01), tornando-se uma alternativa aos critérios rígidos e burocráticos do mercado regulado, os quais aumentam significativamente o custo de transação de um projeto.

Tabela 01 - Evolução do volume e dos preços no Mercado Voluntário de Carbono global

\begin{tabular}{c|c|c}
\hline Ano & Volume $\left(\mathrm{MtCO}_{2} \mathrm{e}\right)$ & Preço Médio (Valor/MtCO $\left.{ }_{2} \mathrm{e}\right)$ \\
\hline 2011 & 97 & 6,2 \\
\hline 2012 & 101 & 5,9 \\
\hline
\end{tabular}

Fonte: Adaptada de Peters-Stanley e Yin (2013).

Quanto aos projetos desenvolvidos, enquanto no Mercado Regulado de Carbono (MRC) estão contemplados apenas projetos de MDL; no Mercado Voluntário de Carbono (MVC), dentre os projetos desenvolvidos no MVC, estão: projetos com metodologias de pequena escala, não viáveis do ponto de vista econômico; projetos que não atendem a critérios estabelecidos pelo MDL; projetos que já computaram créditos retroativos, ou seja, créditos computados antes mesmo do registro do projeto (BENESSAIAH, 2012). Por um lado o MRC possui suas regras e metas de reduções fixadas pelo PK; por outro, o MVC constitui-se em um ambiente no qual as regras e as normas emergem das relações entre os agentes participantes, os chamados Padrões de Certificação (PCs).

Desta forma, segundo Bumpus e Liverman (2008), os desenvolvedores de projetos ou varejistas que atuam no MVC podem se utilizar de regras mais flexíveis, quando comparadas às do MRC, já que a forma de organização do MVC é resultado de ações dos próprios agentes comercializadores de créditos de carbono. Isso porque, a partir das interações entre os participantes, emergem regras que norteiam a comercialização, bem como são padronizadas as formas de negociação com base em acordos emergidos das transações (os PCs) e não especificamente de um tratado ou lei.

Assim, os agentes envolvidos nas transações estabelecem entre si os acordos que vão regulamentar as negociações. Além disso, os meios utilizados para comercializar os créditos de carbono nesse mercado podem estabelecer as suas próprias regras, comuns às partes envolvidas (vendedor e comprador), como o ambiente de negociação americano: a Bolsa de Chicago. A fixação do valor justo na transação emerge do mercado e dos agentes nele atuantes. 
A atratividade nesses mercados está no fator credibilidade que as empresas adquirem frente a seus stakeholders, considerando que as principais motivações não advêm de marco regulatório, bem como de metas a serem cumpridas. As empresas buscam um bom posicionamento nos mercados em que atuam, a partir de ações de responsabilidade socioambiental, bem como aumento da vantagem competitiva frente aos seus concorrentes. A participação de novas empresas nesse mercado se dá também em função dos atrasos nos procedimentos de validação de projetos no mercado regulado (GUIGON et al., 2009; SIMONI, 2009). Contudo é importante salientar que - embora as empresas utilizem o MVC como um meio para obtenção de créditos de carbono ou como forma de testar um projeto também submetido ao MRC, aguardando validação ou aprovação estas não podem comercializar os mesmos créditos para fins de compensação duas vezes.

De acordo com os dados de Peters-Stanley e Gonzalez (2014), as empresas privadas ainda se constituem nos agentes mais expressivos do MVC. Segundo os autores, as empresas privadas participantes do MVC mundial são, em sua maioria, grandes corporações que, juntas, transacionaram, em 2013, 20,3 $\mathrm{MtCO}_{2} \mathrm{e}$, enquanto que as empresas de médio porte transacionaram $9 \mathrm{MtCO}_{2 \mathrm{e}}$ e empresas de pequeno porte, 6,2 $\mathrm{MtCO}_{2} \mathrm{e}$, totalizando $35 \mathrm{MtCO}_{2} \mathrm{e}$. Entretanto a participação dos governos, quer sejam nacionais ou subnacionais, além de agências públicas multilaterais, também tem crescido, tendo desempenhado um importante papel. Peters-Stanley e Gonzalez (2014) destacam ainda que, no ano de 2013, os atores citados foram responsáveis por $15 \%$ dos projetos no mundo e $19 \%$ do volume de créditos adquiridos (atuando como compradores para compensação).

Embora as organizações busquem o MVC por diversos interesses, esse mercado apresenta falhas que impactam diretamente a credibilidade das VER negociadas. Tais falhas estão associadas às características de mensuração, fiscalização, contabilização das reduções de emissões, dentre outras, essenciais ao mercado de offset. No entanto, com o estabelecimento dos padrões de certificação, a partir da mobilização dos agentes participantes desse mercado, as regras instituídas visaram dar ao mercado a credibilidade necessária para seu efetivo funcionamento.

\section{Cobenefícios dos projetos do mercado de carbono para o desenvolvimento sustentável}

Um dos princípios do Protocolo de Kyoto é que os projetos de MDL, cujos créditos de carbono são comercializados no mercado regulado, deveriam atender a dois objetivos: reduzir as emissões de gases do efeito estufa nos países em desenvolvimento e contribuir para o desenvolvimento sustentável. Desta forma, os países em desenvolvimento não só receberiam investimentos com a sua implantação, como também outros benefícios, em consonância com os princípios do desenvolvimento sustentável (SEIFFERT, 2009).

Particularmente para o mercado regulado, esses cobenefícios seriam aqueles não associados diretamente à redução das emissões de carbono derivada de projetos de MDL. De modo geral, esses benefícios incluem melhora na qualidade do ar e da água, intensificação na preservação do solo, proteção contra enchentes, energia elétrica para áreas rurais ou remotas, e aumento nas oportunidades de emprego.

Entretanto o desenvolvimento sustentável tem sido difícil de perceber por causa de problemas de negociação, a exemplo da soberania nacional, e pelo fato de não haver um consenso sobre os critérios e os indicadores para determinação e avaliação dos cobenefícios. Para Bumpus e Cole (2010), a maior dificuldade reside na sua operacionalização de forma realista. Os cobenefícios dependem, na sua maioria, do local onde 0 projeto está sendo implantado, já que cabe à Autoridade Nacional Designada (AND) determinar os critérios que devem ser atendidos para sua contribuição para o desenvolvimento sustentável. Em geral, as decisões tomadas pelas autoridades atendem a um contexto específico, baseado em prioridades nacionais e institucionais, demandas do mercado e participação (ou não) dos interessados.

Desta forma, a Convenção Quadro das Nações Unidas sobre Mudanças Climáticas (CQNUMC) internacionalmente conhecida pela sigla UNFCCC, do inglês United Nations Framework Convention on Climate Change - realizou um estudo sobre quanto um projeto de MDL contribui para o desenvolvimento sustentável. Para tanto, foi elencada uma lista de 10 indicadores - que cobrem as três dimensões clássicas do desenvolvimento sustentável: econômica, ambiental e social - por meio dos quais 3.864 projetos em todo o mundo foram analisados e assim a natureza de sua contribuição para o desenvolvimento sustentável pode ser avaliada. $O$ referido estudo demonstrou que os cobenefícios mais frequentes são a dinamização da economia local, incluindo a criação de emprego e redução da pobreza (29\%), a redução da poluição (22\%) e a promoção da energia renovável (19\%). Ademais, verificou-se que as declarações de cobenefícios ambientais ( $49 \%$ dos

Revista Alcance - Eletrônica - vol. 22 - n. 4 - out./dez. 2015 
projetos) e cobenefícios econômicos (45\%) eram largamente superiores às de cobenefícios sociais $(6 \%)$ (UNFCCC, 2012). Diferentemente, os estudos de Olsen e Fenhann (2008) constataram distribuição similar dos cobenefícios entre as três dimensões, sendo a dimensão social mais reivindicada, seguida pelas dimensões econômica e ambiental.

O país anfitrião pode ter um efeito sobre o mix de cobenefícios, já que cabe à AND determinar os critérios que devem ser atendidos para promoção do desenvolvimento sustentável. O estudo da UNFCCC (2012) concluiu, com base nas inúmeras reivindicações declaradas nos Documentos de Concepção dos Projetos (DCP) de MDL, que há uma forte tendência de contribuição para o desenvolvimento sustentável no país de acolhimento. Já Boyd et al. (2009) observam que, anos após a implementação do MDL, na prática, o objetivo de promover o desenvolvimento sustentável nem sempre vem sendo atendido. De acordo com os autores, isso se dá porque os critérios a serem estabelecidos estão sob a responsabilidade dos governos dos países hospedeiros, que nem sempre os definem de forma clara e mensurável, preocupando-se apenas em conseguir investimentos por meio desse mecanismo que é o mercado regulado de carbono.

Já no mercado voluntário, alguns dos vários padrões de certificação, criados com a finalidade de conceder credibilidade e transparência, têm solicitado que os projetos gerem cobenefícios ambientais e sociais, ultrapassando a exigência mínima de eliminação ou mitigação das emissões de GEE para concessão de créditos de carbono, como o Brasil Mata Viva Standard; CarbonFix Standard; Climate, Community \& Biodiversity Standard (CCB); Gold Standard (GS); Panda Standard; Plan Vivo Standards e Social Carbon(PETERSSTANLEY E YIN, 2013). Exige-se dos proponentes a obediência a algumas regras no desenvolvimento dos seus projetos, de forma que eles possam assumir uma postura proativa no que diz respeito aos aspectos ambientais e sociais. Assim, esse formato estimula uma maior contribuição dos projetos para a promoção do desenvolvimento sustentável e valoriza no mercado o preço dos créditos de carbono gerados pelos mesmos (GOULART, 2013).

De acordo com Peters-Stanley e Yin (2013), o padrão Voluntary Carbon Standard (VCS) tem estado no topo durante os últimos cinco anos, com 41 milhões de toneladas de carbono equivalente $\left(\mathrm{MtCO}_{2} \mathrm{e}\right)$ de créditos comercializados em 2011. Com volumes bem menores, estavam em segundo e terceiro lugares nesse ano a Climate Action Reserve (CAR), com $9 \mathrm{MtCO}_{2} \mathrm{e}$ de créditos comercializados; e o Gold Standard (GS), com 8,5 $\mathrm{MtCO}_{2} \mathrm{e}$. Cabe ressaltar que o padrão GS passou a estar entre os três maiores padrões em termos de volume transacionado a partir da saída do mercado da Chicago Climate Exchange (CCX) em outubro de 2010. Além disso, nos últimos anos, pode ser observado no MVC o desenvolvimento de um número considerável de Padrões de Certificação, representando um sinal do amadurecimento deste segmento (KOLLMUSS et al., 2010).

Autores como Nussbaumer (2009), Drupp (2011) e Wood (2011) também destacam a maior exigência na comprovação de cobenefícios de alguns padrões de certificação, como CCB, Gold Standard e Social Carbon, que solicitam 0 atendimento a indicadores específicos para mensuração dos benefícios ambientais e sociais, como o envolvimento da comunidade local e a utilização eficiente dos recursos naturais, dentre outros. Portanto se entende que os projetos do MVC registrados por esses padrões de certificação possuem um potencial maior de contribuição para o desenvolvimento sustentável (KOLLMUSS et al., 2008).

\section{PROCEDIMENTOS METODOLÓGICOS}

Para alcance do objetivo deste artigo, foi criado em primeiro lugar um banco de dados dos projetos brasileiros registrados no mercado voluntário de carbono, abrangendo informações essenciais extraídas dos Documentos de Concepção dos Projetos (DCP) que ficam disponíveis ao público. Os sites dos padrões de certificação definidos no relatório de Peters-Stanley e Yin (2013) foram visitados para pesquisar a localização e demais informações dos projetos voluntários de carbono registrados no Brasil.

O corte temporal utilizado para o mapeamento dos projetos do mercado voluntário de carbono foi de janeiro de 2011 até dezembro de 2013. Foram identificados 193 projetos, pertencentes a diversos escopos setoriais, cujas informações foram organizadas em planilha Excel. Do total de projetos, 55 deles $(28,5 \%)$ são pertencentes ao escopo de troca de combustível, o qual engloba projetos que tenham realizado mudança do combustível utilizado e, portanto, pleiteado os créditos de carbono face à adoção dessa prática. Como será visto nos resultados, uma maioria significativa dos projetos desse escopo concentra-se na indústria cerâmica.

Todos os 55 projetos de troca de combustível brasileiros registrados no mercado voluntário tiveram seus DCPs analisados com base no modelo de análise (framework) descrito no Quadro 01 para identificação dos cobenefícios declarados. 
Quadro 01 - Modelo de Análise da Pesquisa

\begin{tabular}{|c|c|c|c|}
\hline CONCEITO & DIMENSÃO & COMPONENTE & INDICADORES \\
\hline \multirow{10}{*}{$\begin{array}{l}\text { Cobenefícios do } \\
\text { Mercado } \\
\text { Voluntário de } \\
\text { Carbono }\end{array}$} & \multirow{10}{*}{$\begin{array}{l}\text { Desenvolvimento } \\
\text { Sustentável }\end{array}$} & \multirow{3}{*}{ Econômico } & $\begin{array}{l}\text { Dinamização da economia local, incluindo a criação de } \\
\text { emprego e redução da pobreza }\end{array}$ \\
\hline & & & Desenvolvimento ou difusão local da tecnologia importada \\
\hline & & & Melhoria da infraestrutura \\
\hline & & \multirow{3}{*}{ Ambiental } & Redução da poluição \\
\hline & & & Promoção de energia confiável e renovável \\
\hline & & & Preservação dos recursos naturais \\
\hline & & \multirow{4}{*}{ Social } & Melhoria das condições de saúde e segurança \\
\hline & & & Envolvimento da Comunidade Local \\
\hline & & & Promoção da educação. \\
\hline & & & $\begin{array}{l}\text { Empoderamento das mulheres, o cuidado das crianças e } \\
\text { dos frágeis. }\end{array}$ \\
\hline
\end{tabular}

Fonte: Adaptado de UNFCCC (2012).

Esse modelo de análise foi construído com base no estudo realizado pela UNFCCC (2012) para o mercado regulado e discutido anteriormente neste artigo. A análise dos documentos de concepção dos projetos utilizou a seguinte lógica: sinalização com '+1' quando observada no documento uma contribuição positiva para o desenvolvimento sustentável; sinalização com ' 0 ' se não foi mencionada contribuição; e sinalização com '1 'quando identificada uma contribuição negativa para o desenvolvimento sustentável.

Além dos DCPs, foram buscados outros documentos que apoiaram na concepção dos projetos. Assim, realizou-se uma pesquisa bibliográfica e documental, de caráter exploratório, por meio de consulta a livros, relatórios corporativos, periódicos nacionais e internacionais, artigos científicos nacionais e internacionais, relatórios técnicos, bases de dados nacionais e internacionais, bem como sites institucionais.

Dentre os 55 projetos do escopo de troca de combustível pesquisados, o projeto Dori foi escolhido como estudo de caso ilustrativo devido ao fato de tratar-se da única indústria do setor alimentício que negociou projeto no mercado voluntário de carbono envolvendo troca de combustível fóssil por resíduos de biomassa. A análise do documento de concepção do projeto Dori foi complementada com uma pesquisa de campo visando comparar e verificar os cobenefícios declarados no DCP com os encontrados na realidade. Na visita feita ao projeto Dori, foram entrevistados os desenvolvedores do projeto e as comunidades locais, a fim de verificar as informações dos documentos. Além disso, os indicadores do Quadro 01 foram usados para orientar a avaliação dos cobenefícios gerados neste estudo de caso.

\section{RESULTADOS}

\section{O Mercado Voluntário de Carbono no Brasil}

O Brasil, tanto na esfera federal quanto na estadual e municipal, vem criando nos últimos anos políticas públicas voltadas para combater as mudanças climáticas. Por meio da Política Nacional de Mudanças Climáticas (PNMC), o governo brasileiro pretende reduzir, voluntariamente, de $36,1 \%$ para $38,9 \%$ suas emissões de gases do efeito estufa em relação a projeções futuras até 2020, estimulando o desenvolvimento de projetos de MDL (mercado regulado) e projetos de redução e/ou mitigação de GEE (mercado voluntário) no país (BRASIL, 2009). Em decorrência desta postura proativa, a participação do Brasil nos mercados de carbono tem sido expressiva: no mercado regulado, atualmente é o terceiro país em implementação de projetos de MDL, somente atrás da China e da Índia; e no mercado voluntário, é o país da América Latina que hospeda a grande maioria dos projetos de redução destes gases.

Assim como no cenário internacional, no mercado voluntário de carbono brasileiro a liderança do padrão de certificação Voluntary Carbon Standard (VCS) se repete, porém com maior intensidade ainda.

Revista Alcance - Eletrônica - vol. 22 - n. 4 - out./dez. 2015 
Enquanto no mundo o VCS tem $58 \%$ do mercado voluntário de carbono, no Brasil esse padrão foi adotado em $88 \%$ dos projetos, sendo que $61 \%$ destes adotaram apenas o padrão VCS e $27 \%$, uma associação entre os padrões VCS e SC (Social Carbon). Entre os motivos para essa hegemonia do VCS, estão a facilidade de operação, o menor número de exigências e a similaridade com as regras do mercado regulado. Outro motivo atribuído à hegemonia do padrão VCS foi o sucesso da associação de sua metodologia com a do padrão SC, uma vez que Social Carbon fornece metodologia para incorporar no projeto de redução de emissões de GEE a mensuração dos cobenefícios ambientais, sociais e financeiros. Vale ressaltar que o padrão VCS, similarmente às regras do mercado regulado, concentra-se apenas na exigência da redução de emissões dos gases de efeito estufa; os únicos padrões de certificação que atuam no MVC brasileiro que solicitam 0 atendimento a cobenefícios são: o Social Carbon, oGold Standard e o Climate, Community \& Biodiversity Standard.

No Brasil, os projetos do MVC podem ser divididos em sete escopos setoriais, a saber: eficiência energética, energia renovável, reciclagem, reflorestamento, resíduos, manuseio e tratamento de dejetos animais e troca de combustível. A Figura 01 demonstra a divisão por escopo setorial dos projetos registrados até dezembro de 2013 no MVC brasileiro, mapeados por esta pesquisa. Nota-se que quase 50\% dos projetos enquadram-se no escopo de manuseio e tratamento de dejetos de animais - 0 qual apresenta uma concentração na atividade de suinocultura - e que o escopo troca de combustível é o segundo maior escopo em quantidade de projetos, representando $28,5 \%$ do MVC brasileiro, com 55 projetos com DCPs elaborados e disponíveis para consulta.

Figura 01 - Percentual de Projetos por Escopo Setorial

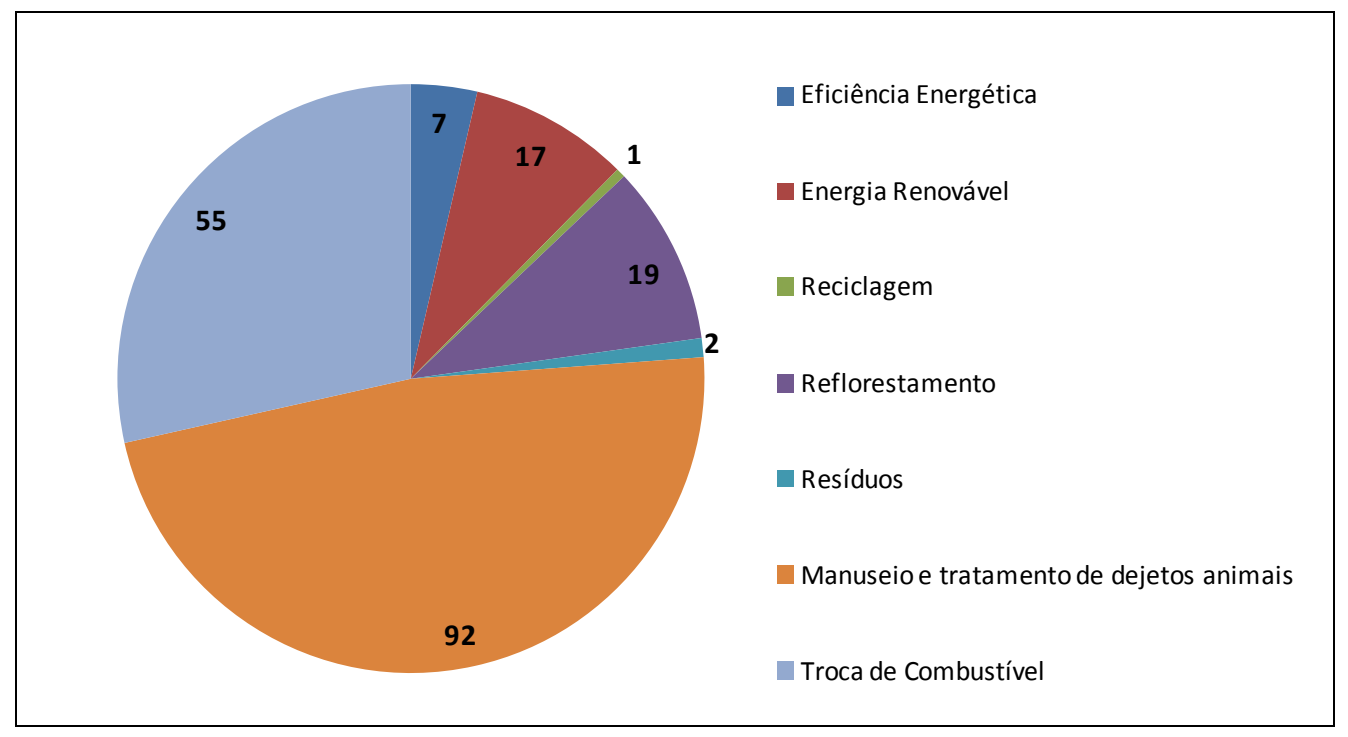

Fonte: Elaborada pelos autores (2014).

\section{Perfil dos projetos brasileiros de troca de combustível e seus cobenefícios}

O escopo de troca de combustível consiste na substituição do combustível mineral, que possui alta quantidade de carbono, como carvão, petróleo e óleo, por outro combustível, de natureza renovável ou um combustível fóssil menos poluente. Este escopo pode ser subdividido em três subescopos, a saber: troca de combustível proveniente de mata nativa (lenha) por resíduos de biomassa; troca de combustível fóssil por resíduos de biomassa e troca por combustível fóssil por outro menos poluente. No Brasil, a imensa maioria dos projetos realiza tanto troca de combustível proveniente de mata nativa (lenha) como troca de combustível fóssil por resíduos de biomassa, que é um combustível de natureza renovável. 0 único projeto registrado que não utilizou os resíduos de biomassa como novo combustível foi o da empresa International Paper, que fez a troca do óleo diesel pelo gás natural.

Portanto os projetos brasileiros classificados neste escopo utilizam resíduos de biomassa (como bagaço de cana, bagaço de coco, capim elefante, aparas de madeira, entre outros) ou um combustível fóssil menos poluente, como o gás natural, como substitutos dos combustíveis fósseis para gerar energia, seja ela em forma 
de eletricidade ou vapor. A proposta da maioria dos projetos é utilizar resíduos de biomassa disponível na região, já que assim os custos com logística e transporte seriam reduzidos.

Conforme pode ser visto na Figura 02 , a maioria esmagadora dos projetos de troca de combustível tem como atividade principal a indústria de cerâmica: são 48 projetos, que representam $87 \%$ do total desse escopo. Deve-se ressaltar que a indústria de cerâmica é a segunda maior atividade presente nos projetos do mercado de carbono brasileiro. Nos projetos desenvolvidos dentro do escopo troca de combustível, as indústrias de cerâmica substituem sua matriz energética movida a óleo diesel ou mata nativa (lenha) - sendo esta última mais frequente - por resíduos de biomassa para geração de energia (PAIVA et al., 2012).

Figura 02 - Projetos por atividade do escopo troca de combustível

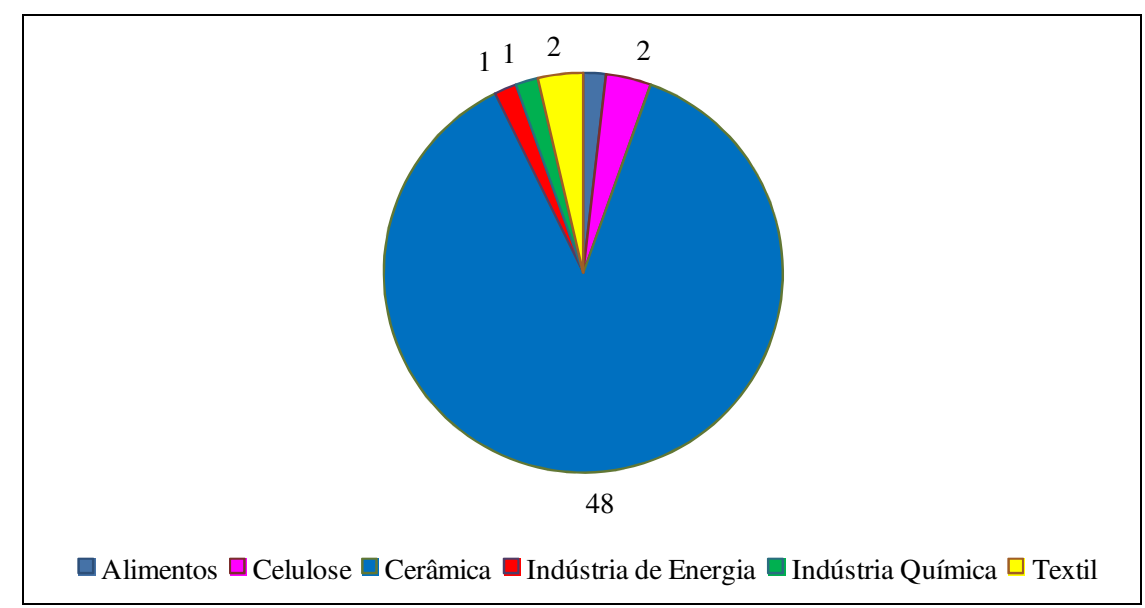

Fonte: Elaborada pelos autores (2014).

Cabe observar que, em países em desenvolvimento, como o Brasil, a taxa de desmatamento de florestas nativas é diretamente proporcional à concentração de gases de efeito estufa na atmosfera, intensificando o aquecimento global, e que este tipo de madeira (lenha) é considerado uma biomassa não renovável, uma vez que não é originado em áreas com atividades de reflorestamento.

Para Rezende (2009), devido ao alto grau de informalidade do setor de cerâmica e à urgência no retorno do investimento a ser realizado, o MVC torna-se mais atrativo para essa atividade. $O$ autor ressalta que, em países em desenvolvimento, tais mecanismos podem se tornar importantes fontes de capital, dada a vasta disponibilidade de recursos renováveis e o grande potencial de desenvolvimento de projetos voltados para a sustentabilidade ambiental.

Espacialmente, os projetos do escopo de troca de combustível estão concentrados na região Sudeste, refletindo a própria concentração da economia brasileira, conforme pode ser inferido da Figura 03. Somando os percentuais de São Paulo, Rio de Janeiro e Minas Gerais, tem-se que $62 \%$ dos projetos de troca de combustível estão localizados nesta região. 
Figura 03 - Projetos por Estado do escopo troca de combustível

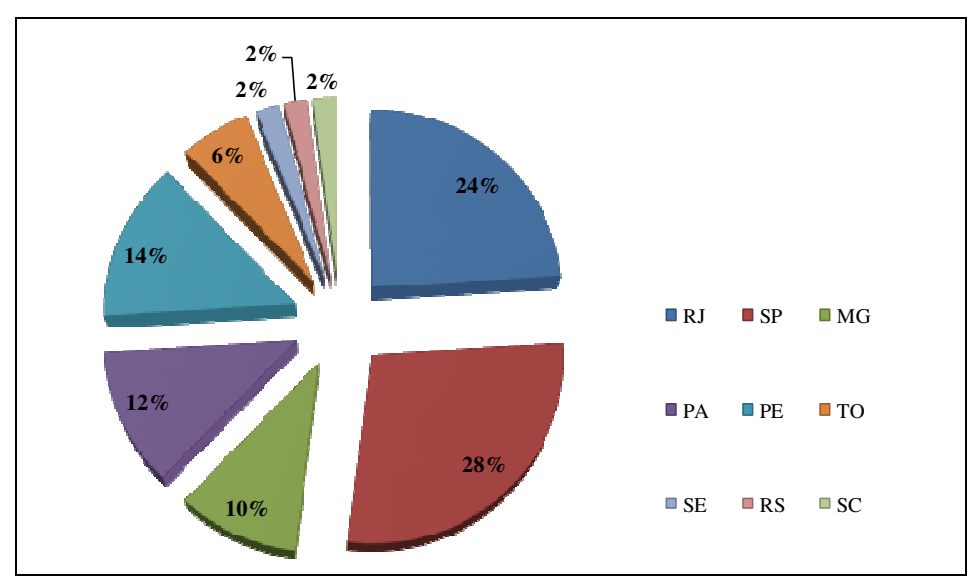

Fonte: Elaborada pelos autores (2014).

Seguindo o mesmo comportamento do mercado mundial, $95 \%$ dos projetos do escopo de troca de combustível (52 projetos) foram registrados pelo padrão VCS. Os demais foram registrados nos padrões ACR, GS e CCX, com apenas um projeto para cada um destes padrões. Dos 52 projetos registrados pelo VCS, 44 tiveram seu registro também no padrão $\mathrm{SC}$, que enfoca cobenefícios econômicos, sociais e ambientais.

As metodologias utilizadas para cálculo da redução de emissão de gases de efeito estufa estimada e realizada na maioria dos projetos foram: AMS-I.E: Switch from non-renewable biomass for thermal applications by the user, com a maioria dos projetos (63\% do escopo, num total de 35 projetos), seguido da metodologia AMS-I.C: Thermal energy for the user with or without electricity, com 31\% do escopo, num total de 17 projetos.

Por meio da análise documental dos DCPs, foi possível constatar os cobenefícios pretendidos quando da implantação do projeto de redução de emissões de GEE listados na Figura 04. Os projetos desse escopo possuem declarações de cobenefícios bastante similares, sendo que todos declaram positivamente os cobenefícios de desenvolvimento ou difusão local da tecnologia e preservação dos recursos naturais, os quais estão intrinsecamente relacionados.

Figura 04 - Cobenefícios dos projetos de Troca de Combustível Fóssil

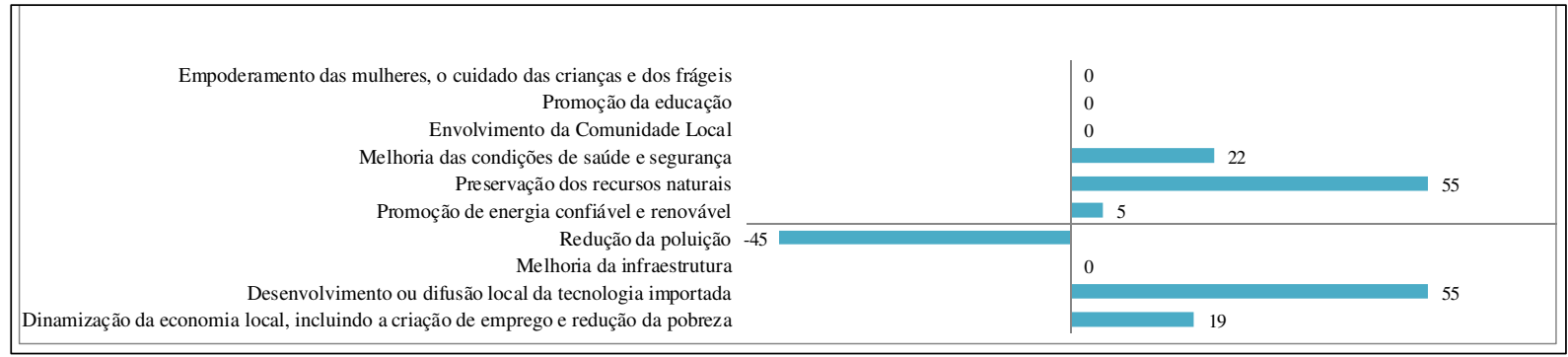

Fonte: Elaborada pelos autores (2014).

Para que seja possível preservar os recursos naturais e com isso determinar os créditos de carbono de cada projeto oriundos da mudança no combustível utilizado para geração de energia, os proponentes devem adquirir máquinas e equipamentos, na maioria das vezes importados, e adaptar às suas plantas para que sejam empregados resíduos de biomassa. Isso porque para a queima de resíduos de biomassa de forma energeticamente eficiente é necessária a reconstrução de entradas do forno. Assim, alguns DCPs relatam como possiveis dificuldades o grande investimento econômico na aquisição do novo maquinário e na adaptação da planta, assim como os desafios na reconfiguração da logística interna e, por fim, a resistência e a falta de conhecimento dos trabalhadores em relação à nova tecnologia. 
Os DCPs dos projetos também declaram que a geração de energia térmica a partir da combustão de resíduos de biomassa, além de preservar os recursos naturais (uso de fonte renovável em vez de não renovável), constitui uma inovação para as indústrias proponentes. Há uma tendência de aumento na demanda deste combustível alternativo, no entanto os DCPs declaram que este aumento é de difícil previsão. Em relação à oferta, existe uma grande quantidade de resíduos de biomassa disponível regionalmente, mas sua disponibilidade também não é previsível, o que faz com que os proponentes estejam constantemente em busca de outros tipos de resíduos de biomassa na região.

Dezenove projetos apontaram como cobenefício a dinamização da economia local, incluindo a criação de emprego e a redução da pobreza. Nestes casos, a troca de combustível desencadeia uma sinergia em termos econômicos na região, pois parte dos resíduos de biomassa é produzida na zona rural, apoiando a criação de empregos e a fixação de trabalhadores e gerando renda no âmbito local.

O cobenefício promoção de energia confiável e renovável foi pontuado por cinco projetos desse escopo, já que a troca de combustível seria utilizada para geração de eletricidade para parte da planta do proponente. Estes projetos pertencem a indústrias maiores, que visam realizar a cogeração de energia para o processo produtivo com o aproveitamento do calor gerado na queima dos resíduos de biomassa.

Quanto ao cobenefício redução da poluição, cabe uma observação importante: apenas dois projetos apontaram positivamente para esse cobenefício, com redução da poluição do ar na substituição da queima do óleo por resíduos de biomassa, enquanto que 47 projetos (46 de indústrias de cerâmica e o projeto Dori) apontaram negativamente para esse cobenefício. Isto porque a queima de resíduos de biomassa em substituição a lenha ou combustíveis fósseis, apesar de reduzir a emissão de GEE, acarreta emissão de fuligem, piorando a qualidade do ar ao redor da planta. Entretanto os projetos afirmam que esse impacto será mitigado com a adoção de filtros para coleta das cinzas e ou lavadores de gases.

Na dimensão social, apenas o cobenefício de melhoria das condições de saúde e segurança foi pontuado positivamente por 22 projetos. Com a implantação dos projetos, são promovidos treinamentos aos funcionários da empresa, que passa a operar com novo combustível que requer maior cuidado no seu manuseio. As indústrias cerâmicas, em particular, apontaram positivamente esse cobenefício, já que são desenvolvidos cursos de formação extensiva sobre manuseio e condições mais seguras de trabalho, a fim de esclarecer para os empregados os novos procedimentos relacionados com a tecnologia adotada. Portanto claramente não há foco nas condições de saúde; apenas são promovidas ações para melhoria da segurança, necessárias em razão da própria troca de combustível.

A partir deste panorama, pode-se inferir que o fato de os projetos desse escopo estarem concentrados na troca de combustível que auxilia na preservação dos recursos naturais e também no desenvolvimento ou difusão local de tecnologia leva a um reducionismo nas demais ações em prol do desenvolvimento sustentável. É clara a tendência de concentrar as mudanças apenas nesses dois cobenefícios, sendo as demais ações sustentáveis decorrentes da mudança do combustível utilizado ou atendidas por algum dispositivo legal, a exemplo dos ambientais ou de segurança no trabalho.

\section{Estudo de caso ilustrativo: Dori}

A Dori Alimentos Ltda. é uma fábrica de doces, criada em 1967 como uma empresa individual chamada Doraci dos Santos Spila, mas que só começou a produzir na década de 1990, já com o nome atual e os novos proprietários, a família Barion. Nessa época, foi adquirida uma das fábricas de doces mais tradicionais do Estado do Paraná, a "Ouro Verde", situada em Rolândia. Também na ocasião foram criadas as subsidiárias comerciais em Osasco - SP e Porto Alegre - RS. Atualmente, a Dori Alimentos Ltda. tem duas unidades de produção: a sede da empresa, localizada na cidade de Marília (SP), e uma unidade subsidiária na cidade de Rolândia.

Em 2004, a Dori iniciou, em ambas as unidades, a substituição do combustível fóssil utilizado no processo produtivo, o óleo de xisto, por cavacos de eucalipto, lascas de madeira de pinus e cascas de amendoim. Contudo a viabilidade do projeto de redução de emissões de gases de efeito estufa só foi possível em 2005, quando do funcionamento da caldeira à base de resíduos de biomassa sem danos na produção. Antes disso, ambas as unidades realizaram o processo de substituição de forma gradativa, tendo os resíduos de biomassa como combustível.

$\mathrm{Na}$ fabricação de doces, o vapor é utilizado em diversas etapas do processo de produção, a exemplo do fornecimento de calor para aumento da umidade dos ingredientes de alguns doces. Assim, o projeto Dori objetiva mitigar as emissões de GEE com a substituição de óleo de xisto por resíduos de biomassa para 
fornecimento de energia térmica às duas unidades de produção, que passaram a adotar a tecnologia de combustão direta. $O$ proponente descreve em seu DCP inúmeras adaptações a serem realizadas no processo produtivo quando da troca do combustível.

Na ausência do projeto, a quantidade média de óleo de xisto utilizado na sede da Dori gira em torno de 3.544 toneladas por ano para gerar uma média de 47.843 toneladas por ano de vapor na caldeira. Já na empresa subsidiária da Dori, a quantidade de óleo de xisto que seria utilizada é em média 4.077 toneladas/ano para gerar 55.041 toneladas de vapor/ano. Em ambas as unidades, o óleo está sendo gradualmente substituído pelos resíduos de biomassa.

A duração do projeto é de 10 anos, a partir de 2006, com estimativa de redução de 20,4 milhões de toneladas de $\mathrm{CO}_{2}$ equivalente por ano, configurando-o como um projeto de pequena escala, já que as atividades de projeto estão limitadas àquelas que resultem em reduções de emissões menores ou iguais a 60 milhões de toneladas de $\mathrm{CO}_{2}$ equivalente por ano (MCT, 2011). A metodologia utilizada para cálculo foi a Category AMS-I.C: Thermal energy for the user with or without electricity - Version 13 from March 14th 2008, EB 381. Para medição dos créditos de carbono, o projeto utilizou como padrão internacional o VCS associado ao Social Carbon para apuração dos cobenefícios em prol do desenvolvimento sustentável. A Dori teve seu projeto validado em outubro de 2009 e verificado periodicamente pela empresa de auditoria TüVNORD, credenciada no âmbito da UNFCCC, utilizando o padrão VCS 2007.1.

Investimentos foram realizados nas duas unidades, em termos de logística e distribuição, a exemplo da compra de equipamentos de transporte e manuseio, silos, treinamento da equipe, local de armazenamento, entre outros. A troca do maquinário foi necessária, já que anteriormente, com a utilização do óleo de xisto, a caldeira era alimentada por meio de tubos fixos e bombas que permitiam a entrada desse combustível líquido. Para se adaptar ao novo combustível, com características físico-químicas bastante diversas, essas máquinas tiveram de ser alteradas. Portanto cada unidade da Dori Alimentos Ltda. teve que comprar uma nova caldeira, com especificações diferentes. Ademais, para que não houvesse riscos à produção, a substituição foi programada de forma gradativa. 0 investimento mais caro realizado na implantação do projeto foi a aquisição das caldeiras por meio de leasing, num total de U\$ $665.135,84$, acrescido dos custos de instalação nas duas unidades.

A implementação dessa nova tecnologia demanda dos trabalhadores aprendizado em novas técnicas de operação e supervisão das máquinas, o que poderia gerar resistência por parte dos mesmos, levando à diminuição da produtividade. Esta situação exigiu um grande esforço por parte dos administradores ao longo da reconfiguração da logística interna, de modo a minimizar a resistência dos funcionários no que tange aos novos métodos empregados.

A geração de energia térmica, por meio da combustão de resíduos de biomassa, é uma inovação na indústria brasileira, no entanto a demanda futura deste combustível alternativo não é de fácil previsão. Assim, o projeto Dori enfrenta a mesma incerteza em termos de demanda e oferta de resíduos de biomassa que os outros projetos brasileiros do escopo de troca de combustível.

Embora exista atualmente uma grande quantidade de resíduos de biomassa disponível na região do projeto a preços acessíveis, há uma possibilidade de que os preços aumentem, especialmente entre as colheitas, quando pode haver queda de produção de resíduos de biomassa, ou por causa de um aumento demasiado da demanda por biomassa. Como o projeto utiliza resíduos de biomassa como lascas de madeira de pinus e cavacos de madeira de eucalipto, os quais não dependem de safra, o problema de disponibilidade de oferta é atenuado, já que seu preço tende a ser mantido durante todo o ano, minimizando os riscos da sua utilização.

Como pode ser visto na Tabela 02, em seu DCP, a Dori declara positivamente quatro cobenefícios dois relacionados ao componente econômico e dois ao ambiental - e negativamente um ligado à questão ambiental. No componente econômico, além do cobenefício da mudança de tecnologia, o projeto afirma contribuir positivamente para criação de empregos, particularmente no que tange à utilização da biomassa, já que a empresa passa a contratar uma empresa de logística e armazenamento do novo material. Já no componente ambiental, a troca de combustível contribui para a promoção de energia confiável e renovável e para a preservação dos recursos naturais à medida que se utiliza um recurso renovável em vez de um recurso não renovável. O projeto pontua as dificuldades e as incertezas da sua utilização e observa ser uma iniciativa pioneira no Brasil, que serve de incentivo para o desenvolvimento de novas tecnologias. 
Tabela 02 - Cobenefícios Declarados e Verificados do Projeto Dori

\begin{tabular}{|c|c|c|c|}
\hline \multirow{2}{*}{ Componente } & \multirow{2}{*}{ Cobenefício } & \multicolumn{2}{|c|}{ Dori } \\
\hline & & Declarados & Verificados \\
\hline \multirow{3}{*}{ Econômico } & $\begin{array}{l}\text { Dinamização da economia local, incluindo a criação de emprego e } \\
\text { redução da pobreza }\end{array}$ & +1 & +1 \\
\hline & Desenvolvimento ou difusão local da tecnologia & +1 & +1 \\
\hline & Melhoria da infraestrutura & 0 & 0 \\
\hline \multirow{3}{*}{ Ambiental } & Redução da poluição & -1 & +1 \\
\hline & Promoção de energia confiável e renovável & +1 & +1 \\
\hline & Preservação dos recursos naturais & +1 & +1 \\
\hline \multirow{4}{*}{ Social } & Melhoria das condições de saúde e segurança & 0 & 0 \\
\hline & Envolvimento da Comunidade Local & 0 & 0 \\
\hline & Promoção da educação & 0 & 0 \\
\hline & $\begin{array}{l}\text { Empoderamento das mulheres, o cuidado das crianças e dos } \\
\text { frágeis }\end{array}$ & 0 & 0 \\
\hline
\end{tabular}

Fonte: Elaborada pelos autores (2014).

Quanto ao cobenefício de redução da poluição - único declarado negativamente no DCP do projeto Dori - na pesquisa de campo, verificou-se que este cobenefício foi gerado, devendo ser pontuado positivamente. A possibilidade de haver um aumento da poluição atmosférica com a utilização de resíduos de biomassa - pois estes geram material particulado - causou alguns problemas para a Dori. Quando da renovação da licença de operação, foi efetivamente observado um aumento da poluição, de modo que a empresa teve que adquirir um lavador de gases e um sistema de exaustor, visando minimizar problemas para a saúde dos trabalhadores e da comunidade local. 0 sistema exaustor de gases tem a função de arrastar as partículas (areia, serradura) que passam por filtros de ciclone que removem uma parte mais grossa do particulado, sendo o resto do material impuro retirado com a utilização do lavador de gases, liberando vapor de água limpo para a atmosfera. Desta forma, embora pontuado negativamente no DCP, a empresa na prática tem empreendido esforços para atenuação dos efeitos negativos da troca de óleo de xisto.

Quando da realização da visita de campo à comunidade local, um morador desta, Sr. Arlindo Campos (2012, informação verbal), pontuou o cobenefício de redução da poluição de forma positiva. Na visão do entrevistado, a fumaça emitida pelo óleo de xisto era mais poluente que a palha de amendoim e o cavaco de madeira utilizado com o projeto. Ainda, a comunidade está ciente de que, com a implantação do projeto, a Dori está mais preocupada com o monitoramento da produção para o cálculo dos créditos de carbono, como também com o controle da poluição, a fim de evitar problemas perante os organismos de controle ambiental.

Embora não tenha sido pontuado nenhum cobenefício na dimensão social, a empresa elenca uma série de ações iniciadas em 2006 para com seus funcionários que denotam preocupação com a qualidade de vida dos seus empregados. Alguns exemplos são: semana de qualidade de vida ao trabalhador; sistema de gestão integrada, educação ambiental e treinamentos aos funcionários relativos à segurança no trabalho.

Logo, o projeto Dori contribui para o desenvolvimento sustentável, na diversificação e na melhoria das fontes de geração de energia, possibilitando a adoção de novas tecnologias de geração de energia térmica a partir dos resíduos de biomassa renovável. Poucas são as contribuições para os demais cobenefícios em prol do desenvolvimento sustentável, já que a maioria deles decorre da mudança no combustível utilizado e, por conseguinte, da tecnologia adotada.

Desta forma, o projeto Dori - mesmo certificado em mais de um padrão de certificação, sendo um deles - Social Carbon, que requisita cobenefícios adicionais - contribui apenas de forma mediana para 0 desenvolvimento sustentável. Estes resultados diferem do que defendem Nussbaumer (2009), Drupp (2011), Wood (2011) e Kollmuss et al. (2008), de que os projetos do mercado voluntário de carbono registrados pelos 
padrões de certificação mais exigentes na comprovação de cobenefícios possuem um potencial maior de contribuição para o desenvolvimento sustentável.

\section{CONSIDERAÇÕES FINAIS}

O Mecanismo de Desenvolvimento Limpo e o Mercado Voluntário de Carbono podem se configurar como importantes instrumentos de políticas climáticas, em lugar de mecanismos concebidos apenas para impulsionar o desenvolvimento nos países em processo de industrialização. Desde a origem, espera-se que a implantação dos projetos de redução de emissões de gases do efeito estufa possa contribuir para o desenvolvimento sustentável dos países hospedeiros.

Retomando o objetivo do presente trabalho de analisar os cobenefícios para além da redução de gases de efeito estufa, dos projetos do escopo de troca de combustível do mercado voluntário brasileiro, pode-se afirmar que há uma tendência de concentração das mudanças nos aspectos tecnológicos, impactando principalmente os componentes econômico e ambiental, ficando o componente social relegado a segundo plano.

O projeto Dori concentra seus esforços na substituição de combustível fóssil, o óleo de xisto, por resíduos de biomassa, no caso cavacos de eucalipto, lascas de madeira de pinus e cascas de amendoim. Da troca decorre o cobenefício de desenvolvimento ou difusão local da tecnologia, já que o projeto prevê uma série de adaptações necessárias, tais como alterações e adaptações ao processo, criação de um sistema automatizado; aquisição de máquinas e equipamentos, bem como a reconstrução e a ampliação de um galpão onde os resíduos de biomassa devem ser armazenados e mantidos secos para que a caldeira possa operar com maior eficiência.

Portanto sua contribuição se restringe à diversificação e à melhoria das fontes de geração de energia, gerando cobenefícios diretamente relacionados a essa troca: desenvolvimento ou difusão local da tecnologia e preservação dos recursos naturais. Assim, o projeto Dori contribui para o desenvolvimento sustentável, ao se considerar a adoção de novas tecnologias de geração de energia térmica a partir de fontes renováveis. Porém poucas são as contribuições para os demais cobenefícios. Considera-se que este projeto oferece uma contribuição ainda pequena para o desenvolvimento sustentável, uma vez que não foram pontuados cobenefícios no componente social.

Logo, por meio da análise documental dos DCPs desse escopo e das visitas e das entrevistas com os principais atores do estudo de caso ilustrativo - o projeto Dori -, verifica-se que os projetos brasileiros do escopo de troca de combustível acompanham o comportamento dos demais projetos do mercado regulado internacional, contribuindo pouco para o desenvolvimento sustentável. Ademais, os resultados observados nesse estudo corroboram as pesquisas da UNFCCC (2012), em que os cobenefícios sociais são inferiores aos econômicos e aos ambientais, assim como confirmam os argumentos de Boyd et al. (2009) sobre a pequena contribuição para o objetivo do desenvolvimento sustentável.

Recomenda-se para estudos futuros a realização de uma análise por tipologia de projetos, ou seja, concentrar o estudo em um dos escopos setoriais do mercado voluntário de carbono, realizando um exame profundo dos cobenefícios dos projetos em prol do desenvolvimento sustentável e estabelecendo paralelos com outras investigações em outros contextos. Outros estudos podem contribuir para a compreensão do tema por meio da análise dos mesmos projetos com outras metodologias de cobenefícios. Ademais, sugere-se, ainda, a realização de estudo comparativo com o mercado regulado de carbono, a fim de verificar similaridades e divergências.

\section{REFERÊNCIAS}

BENESSAIAH, K. Carbon and livelihoods in Post-Kyoto: Assessing voluntary carbon markets. Ecological Economics. № 77, p. 1-6, 2012.

BAYON, R.; HAWN, A.; HAMILTON, K.. Voluntary Carbon Markets: An International Business Guide to What They Are and How They Work. 2a. ed. Earthscan: London, 2009.

BOYD, E.; HULTMAN, N.; ROBERTS, J.; CORBERA, E.; COLE, J.; BOZMOSKI, A.; EBELING, J.; TIPPMAN, R.; MANN, P.; BROWN, K.; LIVERMAN, D.,. Reforming the CDM for sustainable development: lessons learned and policy futures. Enviromental Science \& Policy. 12, 820-831, 2009. 
BOZMOSKI, A.; LEMOS, M.; BOYD, E. Prosperous Negligence: Governing the Clean Development Mechanism for Markets and Development. Environment. 50 (3), 18-30, 2008.

BRASIL. Lei no 12.187, de 29 de dezembro de 2009. Institui a Política Nacional sobre Mudança do Clima PNMC e dá outras providências. Brasília, 2009. Disponível em: <www.planalto.gov.br>. Acesso em: 20 julho 2011.

BUMPUS, A.; COLE, J. How can the current CDM deliver sustainable development? Wiley Interdisciplinary Reviews: Climate Change. Vol. 1, Jul/Aug. 2010. Pg. 541-547.

BUMPUS, A.; LIVERMAN, D. Accumulation by Descarbonization and Governance of Carbon Offset. Economic Geography. Volume 88. Issue 2. April 2008. Pg. 127 -155.

DRUPP, M. Does the Gold Standard label hold its promise in delivering higher Sustainable Development benefits? A multi-criteria comparison of CDM projects. Energy Policy. 2011.

GOLDEMBERG, J. O Caminho até Joanesburgo. In: TRIGUEIRO, André (Coord.). Meio ambiente no século 21. Rio de Janeiro: Sextante, 2005.

GOULART, R. Análise da Estrutura do Mercado Voluntário de Carbono no Brasil: um estudo exploratório. Dissertação de Mestrado apresentada ao Núcleo de Pós Graduação em Administração - NPGA, Escola de Administração, Universidade Federal da Bahia, 2013.

GUIGON, P.; BELLASSEN, V.; AMBROSI, P. Voluntary Carbon Standards: What the Standards Say. Mission Climate Working Paper. Caisse des Dépôts. Abril. 2009.

IBRI - INSTITUTO BRASILEIRO DE RELAÇÕES COM INVESTIDORES. O Mercado de Carbono. Cadernos IBRI. Série Sustentabilidade. 1. ed. 2009. Disponível em: <http://www.ibri.com.br/download/publicacoes/IBRI_Caderno_1.pdf>. Acesso em: 28 janeiro 2010.

KOLLMUSS, A.; LAZARUS, M.; LEE, C.; LEFRANC, M.; POLYCARP, C. Handbook of Carbon Offset Programs: trading systems, funds protocols and standards - Earthscan, 2010.

KOLLMUSS, A.; ZINK, H.; POLYCARP, C. Making Sense of the Voluntary Carbon Market: A Comparison of Carbon Offset Standards. WWF Germany. 2008. Disponível em: < assets.panda.org/downloads/vcm_report_final.pdf>. Acesso em: 15 abril 2012.

LOMBARDI, A. Créditos de Carbono e sustentabilidade: os caminhos do novo capitalismo. São Paulo: Lazuli, 2008.

MINISTÉRIO DA CIÊNCIA E TECNOLOGIA (MCT). Status atual das atividades de projeto no âmbito do Mecanismo de Desenvolvimento Limpo (MDL) no Brasil e no Mundo. 2011. Disponível em: $<$ http://www.mct.gov.br/upd_blob/0215/215908.pdf>. Acesso em: 30 março 2011.

NUSSBAUMER, P. On the contribution of labelled Certified Emission Reductions to sustainable development: a multi-criteria evaluation of CDM projects. Energy Policy. 37, 91-101. 2009.

OLSEN, K.; FENHANN, J. Sustainable development benefits of clean development mechanism projects: A new methodology for sustainability assessment based on text analysis of the project design documents submitted for validation. Energy Policy. 36(8), 2819-2830, 2008.

PAIVA, D.; ANDRADE, J.; TELESFORO, A.; CAIRO, T.; SCHULTZ, L.; ASSIS, L. Mercado Voluntário de Carbono: co-benefícios para o desenvolvimento sustentável dos projetos brasileiros de cerâmica. Anais do XXVII Simpósio de Gestão da Inovação Tecnológica, Salvador, 2012.

PETERS-STANLEY, M.; YIN, D. Maneuvering the mosaic. State of the voluntary carbon markets 2013. Forest Trends' Ecosystem Marketplace \& Bloomberg New Energy Finance. 2013. Disponível em: http://www.forest-trends.org/documents/files/doc_3898.pdf. Acesso em: 21 junho 2013.

PETERS-STANLEY, M.; GONZALEZ, G. Sharing the Stage: State of the Voluntary Carbon Markets 2014. Executive Summary. Ecosystem Marketplace \& Bloomberg New Energy Finance. Maio. 2014. Disponível em: http://www.forest-trends.org/documents/files/doc_4501.pdf. Acesso em: 22 junho 2014.

REZENDE, D. Biodiversidade e Carbono Social. Dissertação de Mestrado apresentada à Universidade de Aveiro, Departamento de Biologia, Universidade de Aveiro, 2009. 
SEIFFERT, M. Mercado de Carbono e Protocolo de Quioto: Oportunidades de Negócio na Busca da Sustentabilidade. São Paulo: Atlas, 2009.

SILVA-JUNIOR, A. Projetos de Mecanismo de Desenvolvimento Limpo (MDL):promotores de transferência de tecnologia e tecnologias mais limpas no Brasil. 2011. 202f. Tese (Doutorado em Engenharia Industrial) Programa de Pós Graduação em Engenharia Industrial - PEI, Faculdade Politécnica, Universidade Federal da Bahia, Salvador, 2011.

SIMONI, W. Mercado de Carbono. In: FUJIHARA, M.; LOPES, F. Sustentabilidade e Mudanças Climáticas: guia para o amanhã. São Paulo: Terra das Artes Editora: Editora Senac São Paulo, 2009.

SOUTHSOUTHNORTH. Climate Change and the Kyoto Protocol's Clean Development Mechanism. London: ITDG Publishing, 2004.

SOUZA, A.; PAIVA, D.; ANDRADE, J. Perfil do Mercado Voluntário. XIII Encontro Nacional de Gestão Empresarial e Meio Ambiente (ENGEMA). Anais do ENGEMA. São Paulo, 5, 6 e 7 de dezembro de 2011.

UNITED NATIONS FRAMEWORK CONVENTIONS ON CLIMATE CHANGE (UNFCCC).Benefits of the clean development mechanism 2012. Disponivel em: <http://cdm.unfccc.int/about/dev_ben/ABC_2012.pdf>. Acesso em: 23 abril 2013.

WOOD, R. Carbon finance and pro-poor co-benefits: The Gold Standard and Climate, Community and Biodiversity Standards [online] London: International Institute for Environment and Development. 2011. Disponível em: <http://pubs.iied.org/pdfs/15521IIED. pdf> . Acesso em: 23 janeiro 2012. 